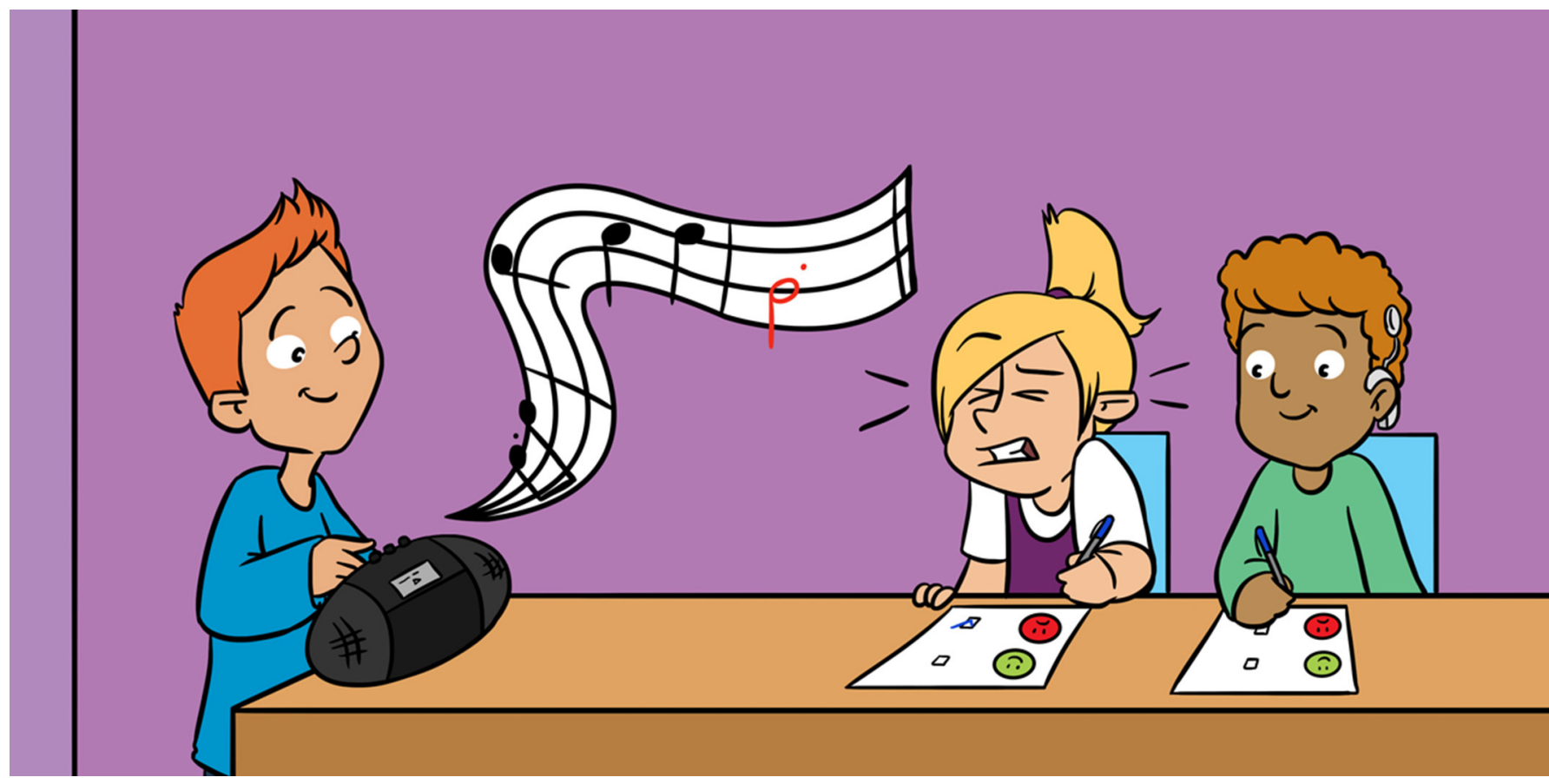

\title{
HOW DEAF KIDS HEAR MUSICAL HARMONY THROUGH A COCHLEAR IMPLANT
}

\section{Victoria Zimmer $^{1,2}$, Jesko Lars Verhey ${ }^{2}$ and Martin Böckmann-Barthel ${ }^{2 *}$}

${ }^{1}$ Augenzentrum Leiterstraße, Magdeburg, Germany

${ }^{2}$ Faculty of Medicine, University Hospital Magdeburg, Magdeburg, Germany

\section{YOUNG REVIEWER:}

FLORENCE

AGE: 8
With cochlear implants, you can make it possible for deaf people to hear again. The people who developed theses cochlear implants were mainly interested in enabling the deaf people to understand what other people say. In this study, we asked ourselves how good a cochlear implant is when listening to music. We worked with children born deaf who have never heard without a cochlear implant. For music, an exact hearing of tones played at the same time is necessary to understand the logic of a lot of music. We call this logic musical harmony. We found that deaf children with cochlear implants are not so different to normal-hearing children when listening to harmony of single notes. However, when listening to tunes they have more difficulties. Thus, understanding music through a cochlear implant seems to be more challenging than understanding speech. 


\section{COCHLEAR}

IMPLANT (CI)

An electronic device that brings back hearing to deaf people. By surgery through the skull, it is positioned at the hearing nerve connecting the inner ear to the brain.

\section{HARMONY}

The musical logic how notes are combined to chords and chords to meaningful music.

Figure 1

A child with a $\mathrm{Cl}$. The earpiece contains three important things: batteries, a microphone, and a processor that calculates the electric impulses needed to trigger the nerve. The information is then delivered through the cable to a coil (the round thing on the head). The coil gives the information to a receiver, which is deep inside the ear, and cannot be seen from the outside. From there, a cable leads into the inner part of the ear and releases the electric impulses to create the impression of a sound.

\section{INTRODUCTION}

Have you ever heard somebody playing a tune on a piano? It is likely that you can easily notice when a piano player hits an incorrect key, because it sounds weird. This is possible even if you are hearing the song for the first time, or even if you do not play the piano yourself. Also, you can probably notice when music arrives at a logical pausing point. You might compare it to the end of a sentence, or the end of a line in a poem. This means that you notice some sort of musical grammar, even without being aware of it.

Now imagine a child who has been deaf since birth or early childhood. Unaided, deaf children cannot hear a honking car horn or listen to music, and they cannot communicate with family and friends using spoken language. In most of these children, some hearing can be restored by inserting a device called a cochlear implant $(\mathbf{C I})$ into the inner ear (Figure 1). This device triggers the nerve that connects the inner ear to the brain. Although the way the device transfers sounds is somewhat coarse, most $\mathrm{Cl}$ users understand speech very well. Think about a blurred photo of your family, in which you can still recognize your parents.

We wanted to know if $\mathrm{Cl}$ users sense musical harmony similarly to the way normal-hearing people sense it [1]. Music helps with skills including learning a language, reading, and understanding math. Thus, if $\mathrm{Cl}$ users sense musical harmony in a similar way normal-hearing people do, it is likely that music can have the same positive effect on their development of these skills.

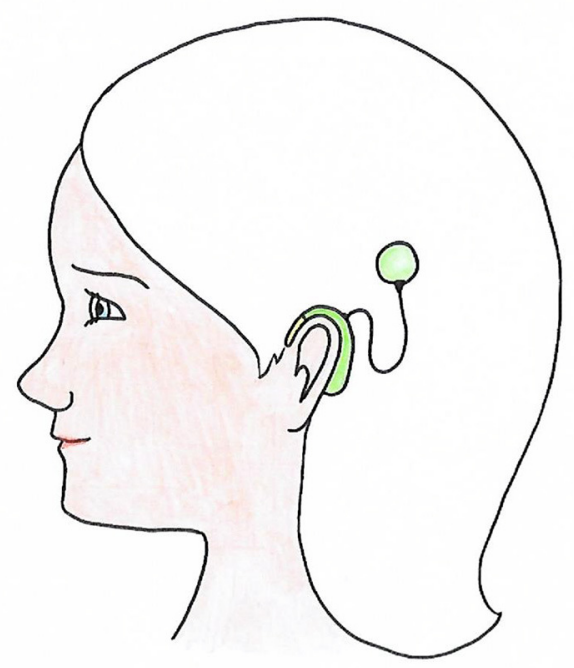

Figure 1 


\section{WHAT WAS OUR EXPERIMENT?}

To understand how $\mathrm{Cl}$ users perceive sounds and how sound heard using a $\mathrm{Cl}$ compares to normal hearing, we invited $\mathrm{Cl}$ users and normal-hearing people to participate in our listening experiments. We designed these experiments to test certain aspects of how people hear sounds. In an earlier study, we investigated how music is heard by adults who grew up with normal hearing but lost their hearing later in life [2]. For these listeners, the music experience they gained before their hearing loss might affect how they sense music with a $\mathrm{Cl}$. In contrast, our $12 \mathrm{Cl}$ users were all born deaf or lost their hearing early, so they could not develop any musical knowledge before they received a $\mathrm{Cl}$. The $\mathrm{Cls}$ were inserted into their ears at about $1-2$ years of age. We also tested 24 normal-hearing children to understand how well children performed our experimental tasks when they listened with their own ears.

In our experiments, we examined how the children with $\mathrm{Cls}$ and the normal-hearing children experienced musical chords. Musical chords are assembled from several tones played the same time, like when certain piano keys are pressed together. Depending on which tones are combined, some chords give a pleasant and soothing (consonant) sensation. If you play a piano, you might know this impression from the combination C-E-G, a so-called major chord. It sounds particularly clear and solid. If you instead play C-E-G sharp, it sounds quite scraping and tense. Such chords generate an unpleasant and disturbing (dissonant) sensation.

\section{DISSONANT}

Sounding unpleasant rough or disturbing.

\section{VIDEO 1}

First, there are the four sounds from experiment 1 : consonant 1 , consonant 2, dissonant 1 , and dissonant 2 . In each trial, two sounds should be compared. Starting from 00:25, there is a song example from experiment 2 in two versions: the first one ends with an odd, improper final sound. From 00:39 on, the sound is played again, ending with the correct sound.

Our first question was whether $\mathrm{Cl}$ users and normal-hearing people prefer the same types of chords. Most normal-hearing people prefer pleasant/consonant chords to unpleasant/dissonant chords. We selected four of the most common chords. Two of them were pleasant/consonant chords (the first one was in fact the major chord). The other two chords were unpleasant/dissonant. Listen to these four chords in Video 1. The chord sounds were presented in pairs. After each presentation, our listeners had to choose the more pleasant sound from the pair.

Our second experiment tested whether $\mathrm{Cl}$ users noticed a musically expected ending, the way you notice when a sentence ends. We selected eight different tunes known to the children in our country (Germany). You might know some of them, like "Happy Birthday" or Brahms' "Lullaby." The tunes were played in three variations: the original one (musically correct) and two modified versions, with the last chord exchanged for an unpleasant one. After each presentation, our listeners had to decide whether the ending of the tune was fine or odd-sounding. 
Figure 2

(A) Light blue dots show the average preferences of the $\mathrm{Cl}$ users for single chords. (B) Yellow diamonds show the average chord preferences of the normal-hearing children. In both panels, the long ovals show how much the different listeners vary. The colors in the background show intensity: the greener the green color gets, the more the chord is favored. The redder the red color gets, the more the chord is disliked. These results show that $\mathrm{Cl}$ users prefer the same chords the normal-hearing children

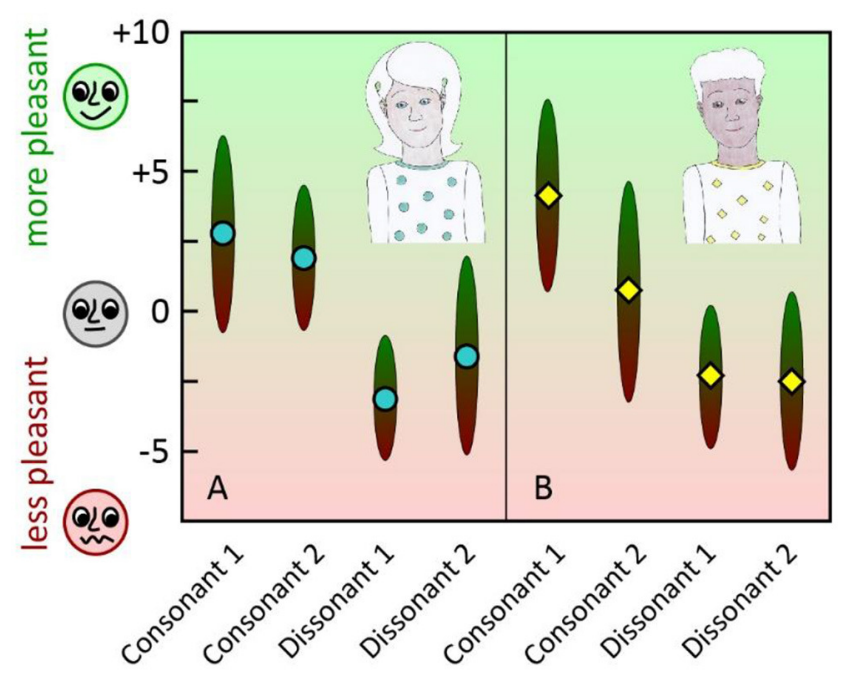

Figure 2

\section{WHAT DID WE FIND?}

Figure 2 shows the results of our first experiment. The normal-hearing children preferred the consonant chords. The two dissonant chords were less favored. This is what we expected, based on musical theory. Results from $\mathrm{Cl}$ users look rather similar to those of the normal-hearing children. $\mathrm{Cl}$ users preferred the same chords, consonant 1 and 2, over the two other, dissonant chords.

In the second experiment, our listeners had to decide if the song endings sounded fine or odd (Figure 3). The data show that normal-hearing children had no problem with the task-in fact, in most cases, their performances were close to perfect. Only our two youngest listeners showed less-than-perfect performance, but they were only 5 years old. In contrast, $\mathrm{Cl}$ users could not distinguish between an ending that is odd and one that is expected. $\mathrm{Cl}$ users also did not get better at this task with age.

\section{WHAT DO OUR RESULTS MEAN?}

The results of our first experiment show that the sound processed through a $\mathrm{Cl}$ is precise enough to sense how good/consonant or $\mathrm{bad} /$ dissonant a chord sounds. The preferences of $\mathrm{Cl}$ users are very similar to those of children with normal hearing. These results show that a $\mathrm{Cl}$ should provide the information necessary to experience this aspect of music. However, in our second experiment, none of the $\mathrm{Cl}$ users could distinguish an odd-sounding ending from a normal-sounding one, whereas nearly all the normal-hearing children did so with ease. As mentioned before, we did a similar study with grown-ups who had lost their hearing later on in life, and thus had the chance to listen to music with their own ears before receiving 
Figure 3

Each diamond shows the result of a normal-hearing child. The further to the right the diamond is, the older the child. Each dot stands for a child with a $\mathrm{Cl}$. Instead of age, the horizontal positions of the dots show the time since the child got the $\mathrm{Cl}$.

The greener the background, the better they could tell the song endings apart. The redder the background, the less they could perform the task. Perfection is shown by the upper dotted line. You can see that most normal-hearing children scored close to perfection, but all $\mathrm{Cl}$ users reached very low scores.

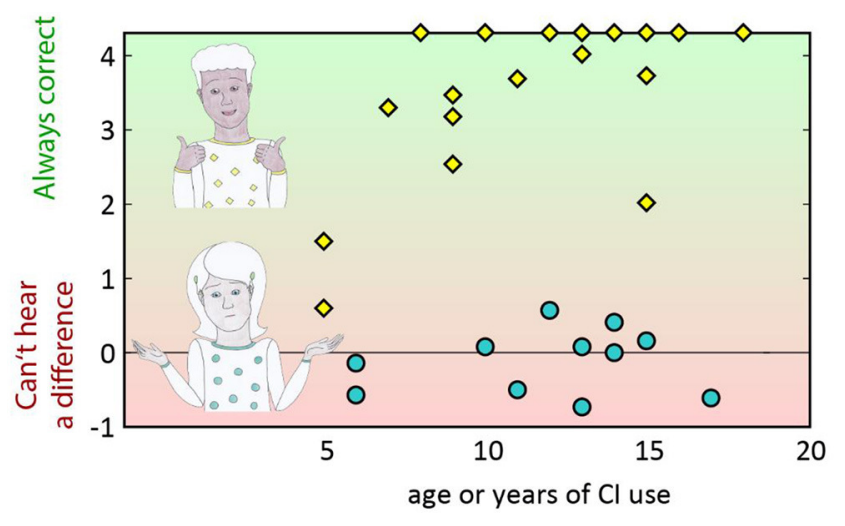

Figure 3

Cls [2]. These listeners also could not tell odd and normal-sounding endings apart from each other. We found the same result in our group of $\mathrm{Cl}$ users who never had the chance to listen to music with their own ears. This result implies that distinguishing normal-sounding vs. odd-sounding song endings is a specific problem of listening through a $\mathrm{Cl}$ and does not depend on having listened to music naturally in the past.

A group from France [3] used sung melodies with chords (some with odd endings and some with expected endings) and measured the time listeners needed to figure out what syllable the singer was pronouncing. In such a task, normal-hearing listeners usually react faster to expected endings. This is because people are usually slowed down by disturbances like unexpected sounds. Surprisingly, the researchers found that $\mathrm{Cl}$ users, reacted faster when the last chord was a musically odd one. They concluded that the $\mathrm{Cl}$ users recognized the difference between expected endings and odd endings, because their reaction times changed with the type of ending. The fact that $\mathrm{Cl}$ users were faster when the last chord was musically odd suggested that they did not find the dissonances disturbing. Remember our initial comparison to looking at a blurred family photo? Imagine that the picture contains enough information to recognize the people in it, but it is too blurred to decide if they are happy or sad. In the same way, $\mathrm{Cl}$ users miss a part of the emotion of the music.

What if children with Cls just need more time to learn? We did not find any tendency toward improvement in these tasks in older children. Nevertheless, we cannot rule out this possibility. Maybe specific listening training, focusing on aspects of music, could help them. This is a question that researchers are working on now. 


\section{CONCLUSION}

In many children who are born deaf, Cls can restore their hearing well enough that they can understand speech. Our study shows that understanding music through a $\mathrm{Cl}$ seems to be more challenging than understanding speech. The ability to tell whether a single musical chord sounds nice or weird, in the same way that normal-hearing people do, does not seem to be enough to allow a grasp of musical grammar. We do not believe that it is impossible for $\mathrm{Cl}$ users to perceive this aspect of music. Focused music training may help $\mathrm{Cl}$ users to learn how a normal song ending sounds. It is also possible that progress in $\mathrm{Cl}$ technology will improve the way music is transmitted to $\mathrm{Cl}$ users. For instance, researchers are trying to understand how the notes in a chord interact through a $\mathrm{Cl}$. It would be nice if future $\mathrm{Cl}$ users could sense musical grammar the same way normal-hearing people do, because only then will they be able to grasp the musical "jokes" and false endings that Mozart and others loved to hide in their pieces!

\section{ORIGINAL SOURCE ARTICLE}

Zimmer, V., Verhey, J. L., Ziese, M., and Böckmann-Barthel, M. 2019. Harmony perception in prelingually deaf, juvenile cochlear implant users. Front. Neurosci. 13:466. doi: 10.3389/fnins.2019.00466

\section{REFERENCES}

1. Zimmer, V., Verhey, J. L., Ziese, M., and Böckmann-Barthel, M. 2019. Harmony perception in prelingually deaf, juvenile cochlear implant users. Front. Neurosci. 13:466. doi: 10.3389/fnins.2019.00466

2. Knobloch, M., Verhey, J. L., Ziese, M., Nitschmann, M., Arens, C., and Böckmann-Barthel, M. 2018. Musical harmony in electric hearing. Interdiscip. J. 36:40-52. doi: 10.1525/MP.2018.36.1.40

3. Tillmann, B., Poulin-Charronnat, B., Gaudrain, E., Akhoun, I., Delbé, C., Truy, E., et al. 2019. Implicit processing of pitch in postlingually deafened cochlear implant users. Front. Psychol. 10:1990. doi: 10.3389/fpsyg.2019.01990

SUBMITTED: 30 April 2021; ACCEPTED: 24 January 2022;

PUBLISHED ONLINE: 01 March 2022.

EDITOR: Christian J. Sumner, Nottingham Trent University, United Kingdom

SCIENCE MENTOR: Samuel Smith

CITATION: Zimmer V, Verhey JL and Böckmann-Barthel M (2022) How Deaf Kids Hear Musical Harmony Through A Cochlear Implant. Front. Young Minds 10:703420. doi: 10.3389/frym.2022.703420 


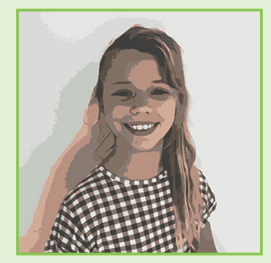

CONFLICT OF INTEREST: The authors declare that the research was conducted in the absence of any commercial or financial relationships that could be construed as a potential conflict of interest.

COPYRIGHT (c) 2022 Zimmer, Verhey and Böckmann-Barthel. This is an open-access article distributed under the terms of the Creative Commons Attribution License (CC BY). The use, distribution or reproduction in other forums is permitted, provided the original author(s) and the copyright owner(s) are credited and that the original publication in this journal is cited, in accordance with accepted academic practice. No use, distribution or reproduction is permitted which does not comply with these terms.

\section{YOUNG REVIEWER}

\section{FLORENCE, AGE: 8}

Hi my name is Florence and I am 8 years old. I am really into art and reading. I have 7 dogs and 3 cats. My favorite activity is horse riding.

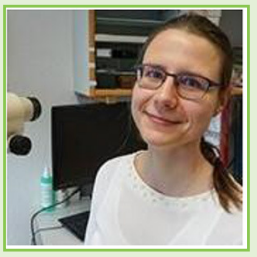

\section{AUTHORS}

\section{VICTORIA ZIMMER}

I am an aspiring ophthalmologist and I started examining deaf people when I was still in medical school. I was so fascinated by cochlear implants that I conducted the study described in this article with my colleagues, for my doctoral thesis. I also worked for some time in a psychiatric hospital with hearing-impaired children, and I learned how to use sign language. Even my hobbies involve seeing and hearing: I am into handcrafts and making music.

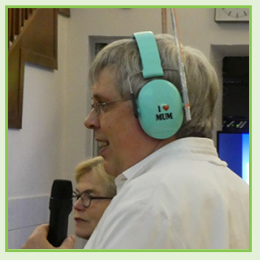

\section{JESKO LARS VERHEY}

My mum was singing in a choir and always had to practice at home when I was a child. That was probably what sparked my early interest in hearing. I am currently a professor at the Otto von Guericke University Magdeburg (Germany) and my interest is understanding not only normal hearing but also what changes when a person's hearing is impaired. Cochlear implants are fascinating devices that can give the hearing experience back to deaf people. I want to know how deaf people with cochlear implants perceive sounds, compared to people with normal hearing.

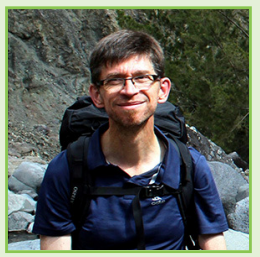

\section{MARTIN BÖCKMANN-BARTHEL}

As a senior researcher, I study how the brain processes sound. With my colleagues, I have investigated how a mixture of sounds separates into different sound sources. I am interested in cochlear implants because they are a great technique for helping deaf people to hear, and I specifically want to understand why music is processed less precisely than speech. Apart from science, music is also an important part of my life, like singing in small choirs and going to concerts. I also like distance running and going on hikes. *martin.boeckmannamed.ovgu.de 